\title{
Efficiency of Air Bubble Removal in Preparation of Low-Profile Angioplasty Balloon Catheter: Bench-Top Comparison of Six Methods
}

\author{
Joon-Ho Choi, RT, MS ${ }^{1,2}$, Seon Moon Hwang, RT, BS ${ }^{1}$, Deok Hee Lee, MD, PhD ${ }^{1,3}$ \\ ${ }^{1}$ Department of Radiology, Research Institute of Radiology, Asan Medical Center, Seoul, Korea \\ ${ }^{2}$ Department of Medical Science, Graduate School of Soonchunhyang University, Ansan, Korea \\ ${ }^{3}$ Departmet of Radiology, University of Ulsan College of Medicine, Seoul, Korea
}

Purpose: Complete removal of air bubbles from balloons for neurovascular angioplasty is cumbersome. We compared the preparation difficulty, air removal efficiency, and air collection pattern of six different balloon catheter preparation methods to propose a better preparation method for both initial and second balloon uses, especially for small-profile angioplasty balloon catheters.

Materials and Methods: A total of 18 neurovascular angioplasty balloon catheters with nominal diameters of $2 \mathrm{~mm}$ were prepared to test six different preparation methods: the instruction for use method (method A), simplified method using a syringe (method B) and four newly devised preparation methods using inflating devices (methods $\mathrm{C}-\mathrm{F}$ ). Serial radiographs were obtained while the balloons were gradually inflated. We measured the time for each preparation and the bubble number, analyzed their distribution in the balloon, and calculated the contrast filling ratio (contrast filling area/total balloon area) for initial and second ballooning. The whole process was repeated three times.

Results: The preparation time varied widely (11.5 seconds [method D] to 73.3 seconds [method A]). On initial inflation, the contrast filling ratio at 8 atm was the highest (100\%) with methods $A$ and $F$. On second inflation, the ratio was again highest with method A (99.5\%), followed by method F (99.2\%). Initial ballooning tended to show a uniform pattern of single bubble in the distal segment of the balloon; in contrast, second ballooning showed varying patterns in which the bubbles were multiple and randomly distributed.

Conclusion: None of the six methods were able to completely exclude air bubbles from the balloon catheters including the second ballooning; however, the method of repeating aspiration with high-volume inflating device (method F) could be a practical option considering the simplicity and efficiency of preparation.

Key Words: Intracranial atherosclerosis; Balloon angioplasty; Air embolism; Device failure

\author{
Correspondence to: \\ Deok Hee Lee, MD, PhD \\ Department of Radiology, Research \\ Institute of Radiology, Asan Medical \\ Center, University of Ulsan College \\ of Medicine, 88 Olympic-ro 43-gil, \\ Songpa-gu, Seoul 05505, Korea \\ Tel: +82-2-3010-5944 \\ Fax: +82-2-476-0090 \\ E-mail:dhlee@amc.seoul.kr \\ Received: August 3, 2018 \\ Revised: November 6, 2018 \\ Accepted: November 8, 2018 \\ Copyright $\odot 2019$ Korean Society of \\ Interventional Neuroradiology \\ This is an Open Access article distributed under the terms of \\ the Creative Commons Attribution Non-Commercial License \\ (http://creativecommons.org/licenses/by-nc/3.0) which \\ permits unrestricted non-commercial use, distribution, and \\ reproduction in any medium, provided the original work is \\ properly cited.
}




\section{INTRODUCTION}

Balloon catheters are routinely used in the neurointerventional field for various purposes including angioplasty for atherosclerotic intra- and extra-cranial stenoses, ${ }^{1-6}$ angioplasty for vasospasm, ${ }^{7}$ and neck remodeling for wide-necked aneurysm coiling. ${ }^{8}$ Recently, balloon-guiding catheters become one of the prerequisites for efficient mechanical neurovascular thrombectomy procedures. ${ }^{9}$ For successful and safe usage of balloon catheters, proper preparation before use is critical, ${ }^{6}$ which includes removal of pre-existing air from the balloon part of the catheter. The issue of residual air bubble may not seem so critical; however, poor preparation could be a potential source of air embolism in case the balloon ruptures, and the presence of radiolucent air bubble in the dilating balloon may interfere proper monitoring of the dilation process on fluoroscopy. ${ }^{10-12}$

The package of balloon catheter includes an "Instruction for Use (IFU)" that describes how to prepare the balloon catheter for proper use and how to remove air from the balloon. Even after following the IFU, however, satisfactory removal of air bubbles from the entire lumen of the balloon catheter is rather challenging. Complete or near-complete removal of air bubbles could be achieved if the negative-pressure aspiration is repeated until there is no more visible air bubble in the aspirating syringe as the IFU directs. ${ }^{6}$ Nevertheless, it is impractical to repeat the aspiration process more than 3-5 times in clinical setting, and the issue of air bubbles during balloon angioplasty remains. Besides the air embolism risk, small amount of residual air within the inflating balloon may interfere proper monitoring of the angioplasty status, especially for low profile balloon catheters that are commonly used during intracranial angioplasty.

We therefore devised new preparation methods using inflating devices and 3-way stopcocks in order to simplify the preparation method and improve air removal efficiency with shortened preparation time. The purposes of these benchtop experiments were to compare the preparation difficulty, air removal efficiency, and air collection pattern among current and newly devised preparation methods and to propose a practical preparation method for both initial and second balloon uses, especially for small-profile angioplasty balloon catheters for neurovascular intervention. In our preliminary experiments, we noticed that the patterns of air bubbles occurred differently between the initial balloon angioplasty and the second angioplasty with the same bal- loon; we therefore sought to examine this issue as well in our experiments.

\section{MATERIALS AND METHODS}

\section{Balloon preparation methods}

Aside from the method in the IFU (method A) and the currently used simplified method using a 10-mL syringe (method B), we also devised four different preparation methods using 20- or 30-mL inflating devices (methods C-F). Details of the methods are described in Table 1 and Supplementary Video 1. The IFU method we adopted for this study was from the package of Gateway balloon angioplasty catheter (Stryker Neurovascular, Fremont, CA, USA), which is one of the most commonly used balloon catheters for intracranial angioplasty. For practicality of the method, we limited the aspiration number to three times. Each method differed in terms of volume of the aspirating syringes $(10 \mathrm{~mL}$ and $20 \mathrm{~mL})$, use of the 3-way stopcocks, use of inflating devices of varying volumes (20 mL and $30 \mathrm{~mL}$ ), number of repetitions, number of syringe connections, and total number of procedural steps. As a result, there were significant differences in the procedural complexity and preparation time.

For all methods, we used iodine contrast media (Visipaque 270; GE Healthcare, Amersham, UK) diluted with normal saline (6:4 in volume) to replace the pre-existing air space in the balloon channel of the catheter. The aspiring syringes and inflating devices were pre-filled with a small amount of the dilated iodine contrast media ( $3 \mathrm{~mL}$ for $10 \mathrm{~mL}$ syringe, $5 \mathrm{~mL}$ for others) to maximize the negative pressure during aspiration.

\section{Test platform setting and image acquisition}

A total of 18 rapid-exchange (monorail) types of neurovascular angioplasty balloon catheters (Treso; CGBio, Seongnam, Korea) were prepared. The nominal diameter of balloon catheters was $2 \mathrm{~mm}$ at $8 \mathrm{~atm}$. The length of the balloon segment was $15 \mathrm{~mm}$, and the balloon part of the catheter was made of nylon. In order to compare six different preparation methods, six balloon catheters were used for one session, and the tests were repeated three times.

The six catheters were placed side-by-side and fixed on the angiography table (Siemens Axiom Artis Zee; Siemens Healthneers. Forchheim, Germany) to prevent any unwanted movement during balloon preparation and inflation since the 
Table 1. Details of the 6 methods

\begin{tabular}{|c|c|c|c|c|c|c|c|}
\hline Method & Description & $\begin{array}{l}\text { Aspirating } \\
\text { device }\end{array}$ & $\begin{array}{l}\text { Syringe } \\
\text { volume } \\
(\mathrm{mL})\end{array}$ & $\begin{array}{l}\text { Number } \\
\text { of syringe } \\
\text { connections }\end{array}$ & $\begin{array}{c}\text { Use of } \\
\text { stopcock }\end{array}$ & $\begin{array}{l}\text { Number of } \\
\text { aspirations }\end{array}$ & $\begin{array}{c}\text { Total } \\
\text { number of } \\
\text { steps }\end{array}$ \\
\hline$A$ & $\begin{array}{l}\text { The method recommended in the IFU. } \\
\text { The 20-mL syringe was connected to } \\
\text { the catheter hub together with a 3-way } \\
\text { stopcock for each aspiration. After each } \\
\text { aspiration, the syringe was disconnected } \\
\text { and cleared of aspirated air for the next } \\
\text { aspiration. }\end{array}$ & Syringe & 20 & 3 & Yes & 3 & 16 \\
\hline B & $\begin{array}{l}\text { A } 10-\mathrm{mL} \text { syringe was directly connected to } \\
\text { the catheter hub for aspiration. For each } \\
\text { aspiration, the syringe was cleared of air as } \\
\text { in method } \mathrm{A} \text {. }\end{array}$ & Syringe & 10 & 3 & No & 3 & 13 \\
\hline C & $\begin{array}{l}\text { A 3-way stopcock was connected to the } \\
\text { catheter hub and the rest of the stopcock } \\
\text { hubs were connected to a 20-mL inflating } \\
\text { device and a 10-mL syringe. After each } \\
\text { aspiration using the inflating device, the } \\
\text { stopcock knob was turned to the syringe } \\
\text { so that the empty catheter lumen can be } \\
\text { filled with the diluted contrast media. Then } \\
\text { the knob was turned back to the inflating } \\
\text { device for the next aspiration, which was } \\
\text { repeated three times. }\end{array}$ & $\begin{array}{c}\text { Inflating } \\
\text { device }\end{array}$ & 20 & 1 & Yes & 1 & 13 \\
\hline D & $\begin{array}{l}\text { A 20-mL inflating device was directly } \\
\text { connected to the catheter hub and } \\
\text { aspirated only once. }\end{array}$ & $\begin{array}{l}\text { Inflating } \\
\text { device }\end{array}$ & 20 & 1 & No & 1 & 4 \\
\hline E & $\begin{array}{l}\text { A 20-mL inflating device was directly } \\
\text { connected to the catheter hub, and } \\
\text { aspiration was carried out three times } \\
\text { without any disconnection in between the } \\
\text { aspirations. }\end{array}$ & $\begin{array}{l}\text { Inflating } \\
\text { device }\end{array}$ & 20 & 3 & No & 1 & 8 \\
\hline F & $\begin{array}{l}\text { Identical to method } \mathrm{E}_{\text {, except for using a 30- }} \text { mL inflating device. }\end{array}$ & $\begin{array}{l}\text { Inflating } \\
\text { device }\end{array}$ & 30 & 3 & No & 1 & 8 \\
\hline
\end{tabular}

IFU, Instruction for Use.

test was performed in the room air condition (Fig. 1). After preparation, a series of digital subtraction radiographs were obtained while each balloon catheter was inflated. The radiographic images were obtained in automatic exposure control mode with the source-to-image receptor distance fixed at $100 \mathrm{~cm}$, field of view of $16 \mathrm{~cm}$, and matrix of 1024 by 960 .

\section{Data acquisition and image analysis}

After completion of each aspiration process, the balloon catheters were connected to a 20-mL inflating device, which was used for all preparation methods requiring inflating devices (methods C, D, E, and F). The balloon portions of the six balloon catheters were radiographed sequentially at $0 \mathrm{~atm}$ (before inflation), 1 atm, 2 atm, 4 atm, 6 atm, and 8 atm. As a result, a total of six sets of images were obtained for each method (Fig. 1). After completion of the initial ballooning, the balloon catheters were deflated completely using the inflating device; then, the inflation processes were repeated for second ballooning and radiographed again following the same sequence of the initial inflation (Fig. 2). We repeated this process in three sets as carried out for the initial ballooning.

The radiographs were digitally subtracted to clearly show the inflating balloon portion, and the patterns of air bubble visualization during inflation were recorded. The number of air bubbles were counted on the images obtained when the balloons were dilated at 4 atm, which we deemed as enough pressure to observe separated air bubbles. The amount of 

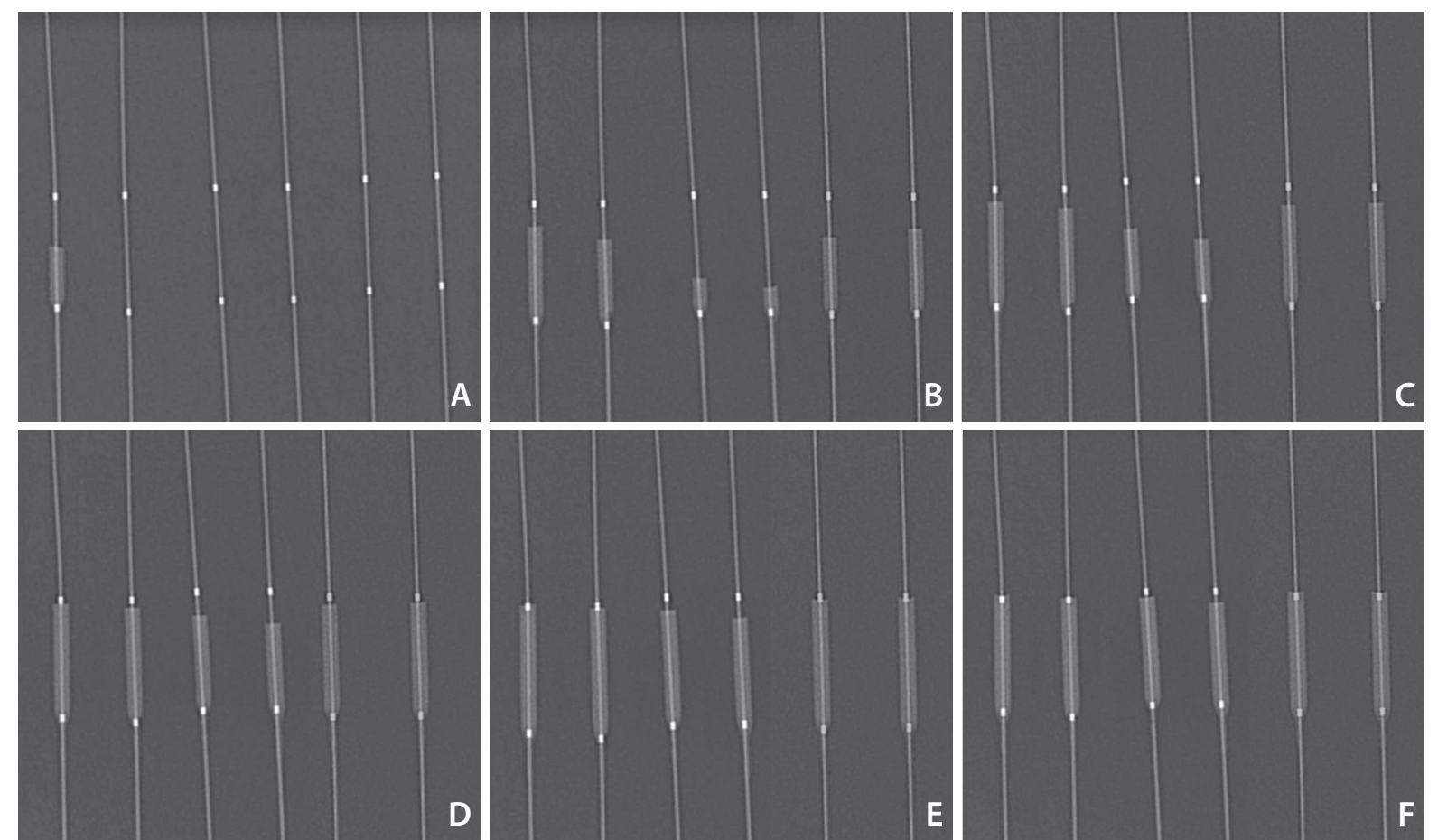

Fig. 1. Radiographs obtained during the initial ballooning. The six balloons were placed side-by-side from method A to method $F$ (left to right). (A) After finishing preparation and right before the inflation at $0 \mathrm{~atm},(\mathbf{B}) 1 \mathrm{~atm},(\mathbf{C}) 2 \mathrm{~atm},(\mathbf{D}) 4 \mathrm{~atm},(\mathbf{E}) 6 \mathrm{~atm}$, and (F) 8 atm, which was the nominal pressure of the balloon catheter.
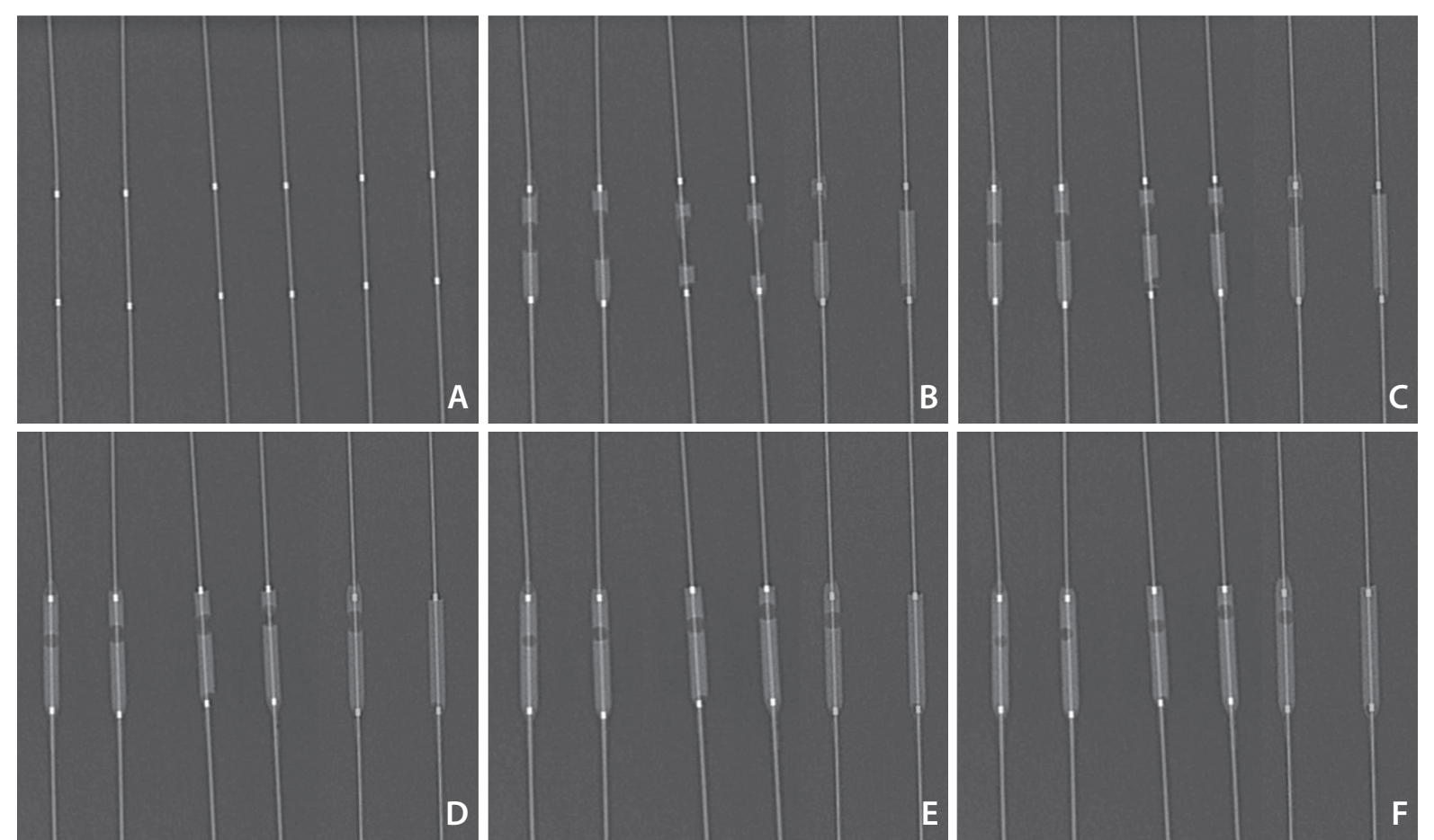

Fig. 2. Radiographs obtained during the second ballooning. The six balloons were placed side-by-side from method $A$ to method $F$ (left to right). (A) After complete deflation and right before the second inflation at 0 atm, (B) 1 atm, (C) 2 atm, (D) 4 atm, (E) 6 atm, and (F) 8 atm. Compared with the initial ballooning, the balloons tend to show multiple air bubbles. Please note additional air bubbles as small defects at the proximal and distal tips of the inflating balloons. 
air bubbles was categorized as none, single, and multiple. On the same image, the distribution of air bubbles was categorized by dividing the balloon part into three segmentsproximal, middle, and distal. We recorded the distribution as "multiple segments" when the bubbles were seen in two or more segments. On each image, the rod-shaped, iodine-filled balloon part was segmented into two portionsair portion and contrast portion —using the ImageJ software (ver. 1.48; US National Institutes of Health, Bethesda, MD, USA). We calculated the contrast filling ratio by dividing the contrast portion area by the total balloon area (air portion and contrast portion) on each image and method. In the measurement of the air portion, sum of the total areas was used in case of multiple bubbles. Arithmetic means of the triplicate test results were compared among the six preparation methods. The same analyses for pattern and contrast filling ratio were carried out for the second balloon inflation.

To measure the duration of preparation time for each method, we measured the duration from the first step to the last step of the preparation using a stop watch. The six balloons used for the 3rd set of the experiment were used

Table 2. Balloon preparation time

\begin{tabular}{lccc}
\hline \multirow{2}{*}{ Method } & No. of & \multicolumn{2}{c}{ Duration (seconds) } \\
\cline { 3 - 4 } & Observations & Mean \pm SD & $95 \% \mathrm{Cl}$ \\
\hline $\mathrm{A}$ & 15 & $76.3 \pm 1.4$ & $75.5-77.1$ \\
$\mathrm{~B}$ & 15 & $53.3 \pm 1.2$ & $52.6-54.0$ \\
$\mathrm{C}$ & 15 & $74.0 \pm 1.0$ & $73.5-74.6$ \\
$\mathrm{D}$ & 15 & $11.5 \pm 0.7$ & $11.1-11.9$ \\
E & 15 & $40.7 \pm 1.1$ & $40.1-41.3$ \\
F & 15 & $41.2 \pm 1.0$ & $40.6-41.8$ \\
\hline
\end{tabular}

$\mathrm{SD}$, standard deviation; Cl, confidence interval.

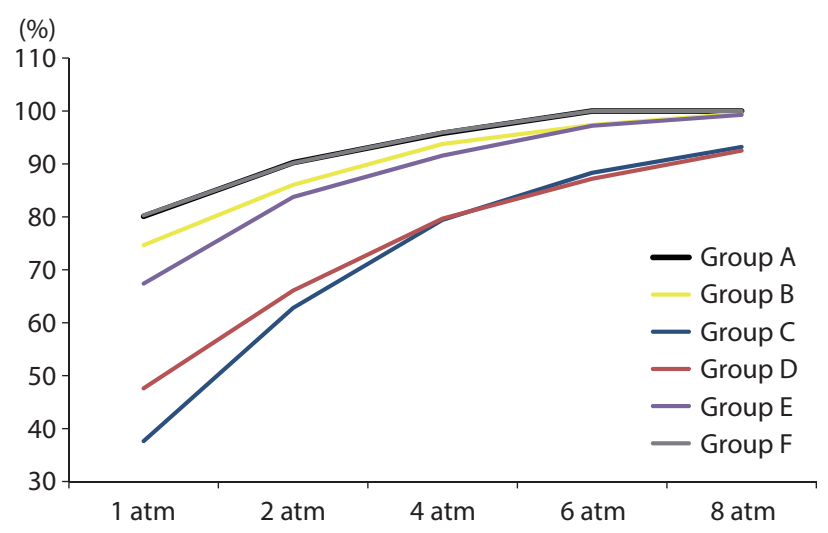

Fig. 3. Contrast filling ratio of the initial ballooning. The best ratio was seen in methods A and method F, whose lines overlapped due to nearly similar values in all pressure points. again. The measurement was repeated 15 times, and their means and 95\% confidence intervals were calculated.

\section{RESULTS}

\section{Balloon preparation time}

The preparation time for each method varied widely and ranged from 11.5 seconds (method D) to 76.3 seconds (method A) (Table 2 and Supplementary Video 1).

\section{Initial balloon dilation}

We observed a gradual increase in contrast filling ratio from $1 \mathrm{~atm}$ to $8 \mathrm{~atm}$ (Fig. 3, Supplementary Table 1). Notably, balloons prepared with method A showed small amount of contrast density even before applying any pressure for dilation, possibly due to a small amount of dilation of the balloon. At $1 \mathrm{~atm}$. the contrast filling ratio ranged from 37.6\% (method C) to $80.3 \%$ (method F), and the ratio increased until they reached $92.5 \%$ (method D) to 100\% (methods A and F) (Fig. 3). The line graphs of methods $A$ and $F$ showed similar curves. At radiographs taken at $4 \mathrm{~atm}$, all methods showed single bubbles, which were located just at the distal apex segment of the balloon; the bubbles gradually decreased in size with increased pressure (Fig. 1, Supplementary Tables 2, 3).

\section{Second balloon dilation}

Similar contrast filling ratio line-graph patterns were seen in the second ballooning (Fig. 4). The initial contrast filling ratio at $1 \mathrm{~atm}$ tended to be higher than those of the initial bal-

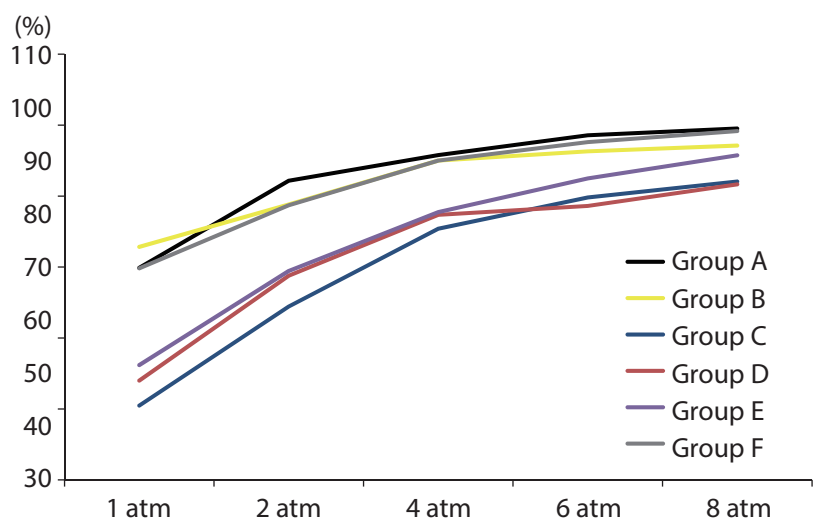

Fig. 4. Contrast filling ratio of second ballooning. The best ratio was seen in method $\mathrm{A}$, followed by method $\mathrm{F}$. 
looning, with a range of $60.5 \%$ to $82.8 \%$; however, the ratio did not reach $100 \%$ even at 8 atm (Supplementary Table 1). The best ratio at $8 \mathrm{~atm}$ was achieved with method A (99.5\%) followed by method $F$ (99.2\%). The number of bubbles tended to be multiple and randomly distributed (Fig. 2, Supplementary Tables 4, 5). The detailed values of the contrast filling ratio of each method at each pressure level are provided in Supplementary Figs. 1-6.

\section{DISCUSSION}

In our bench-top experiments, none of the six preparation methods were able to completely exclude air bubbles from the balloon catheters. Thus, achieving complete air bubble-free balloon dilation may only be possible through lengthy and cumbersome preparation process with multiple aspiration, which poses a practical limitation in clinical settings.

The primary goal of this study was identifying the most efficient and simple preparation method, and we observed that method $F$, which consisted of three times of repeated aspiration using a 30-mL inflating device, was both efficient and easy to execute. In terms of contrast filling ratio, method A showed comparative results with method F; however, when considering procedural simplicity, method $\mathrm{F}$ is superior to method A overall.

Notably, we noticed that the air bubble visualization pattern was different between the initial and second ballooning. During initial ballooning, single radiolucent regions (air bubble) were mostly seen. The bubbles were located at the distal portion of the balloon and further displaced to the tip of the balloon catheter with increasing pressure (Fig. 1). In contrast, on second ballooning, the bubbles tended to be multiple and the locations were relatively random (Fig. 2). We assume that the irregular residual wings of the deflated balloon and the inflated balloon catheter caused effective air removal during the second preparation. This indicates that more attention is needed during repeated preparations after initial ballooning. Because the balloon catheters that were used for pre-stent angioplasty are commonly used again for post-stent angioplasty, great care should be paid whether the balloons are completely collapsed while passing through the stented segment and complete visualization of the balloon during inflation. We assume that the result would be different if the inflated balloons are prepped again after completely disconnecting the inflating device after the initial ballooning.

Another unexpected observation was the small amount of radiopaque contrast media within the balloon segment right after device connection before applying any pressure (at 0 atm) especially with methods A and C (Fig. 1A). We hypothesized that a subtle change in the volume by the connecting process between the catheter hub and the 3-way stopcock pushed the contrast column by a small amount, which was already in the catheter lumen. Because the irregular wing formation of the already inflated balloon may negatively affect the angioplasty/stenting outcome, prior filling of the contrast column in the partially collapsed balloon might exaggerate the problem even though the pushing contrast amount was small.

After observing these results, we began applying method $F$ in our practice and achieved satisfactory results, even in low-profile balloons. One caveat of method $\mathrm{F}$ in practice was

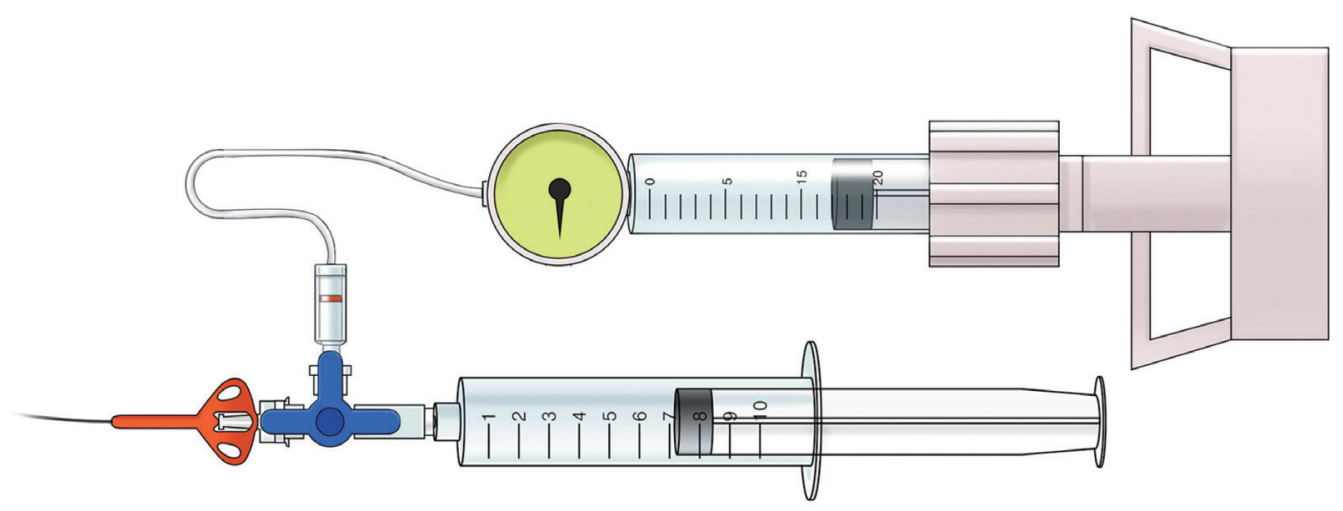

Fig. 5. Possible combination of an inflating device and a syringe for further improvement of preparation efficiency. After repeated aspirations with the inflating device, bubbles aspirated into the barrel of the device can be removed by the syringe using the stopcock. 
the difficulty of handling the inflating device after preparation - we found it a bit cumbersome to keep the air-fluid level, which was caused by air aspirated from the catheter, in the barrel of the device. We expect that the problem would be solved if the air could be removed right after the preparation. Considering this point, we could devise a better preparation method by combining the advantages of methods $A$ and $F$, such as a combination of a 10-mL syringe and an inflating device of any volume (Fig. 5).

There are several limitations of this study. First of all, the number of tests were too small to achieve reproducible test results and to conduct statistical tests for further validation. Due to the limitation of available balloon catheters for testing purposes, we could only achieve three sets of test results for each method. Since the test was done under room air condition, the dynamics of air bubble movement could be different within the body. Nevertheless, our experiments were meaningful in that we gained deeper insight into the mechanism of air removal from balloon catheters. Second, even though we tested six different methods, which might not include the best method one could devise. We believe there could be more effective and simple method or device. Lastly, we assume that the result would be different for balloons with different volumes such as those with diameters of less than or larger than $2 \mathrm{~mm}$.

\section{CONCLUSION}

Although none of the proposed preparation method was able to completely exclude air bubbles from the balloon catheters, we found that repeating aspiration with high-volume inflating device may be a practical alternative option to conventional method, considering the simplicity and efficiency of the preparation.

\section{SUPPLEMENTARY MATERIALS}

Supplementary materials related to this article can be found online at https://doi.org/10.5469/neuroint.2018.01074 .

\section{Acknowledgments}

This research was supported by a grant (2017 KSIN research support grant) from the Korean Society of Interventional Neuroradiology.

We are thankful for CGBio, Ltd. for providing us the balloon catheters required for this experiment.

\section{REFERENCES}

1. Fiorella D, Chow MM, Anderson M, Woo H, Rasmussen PA, Masaryk TJ. A 7-year experience with balloon-mounted coronary stents for the treatment of symptomatic vertebrobasilar intracranial atheromatous disease. Neurosurgery 2007;61:236-242; discussion 242-243

2. Karanam LSP, Sharma M, Alurkar A, Baddam SR, Pamidimukkala V, Polavarapu R. Balloon angioplasty for intracranial atherosclerotic disease: a multicenter study. J Vasc Interv Neurol 2017;9:2934

3. Suh DC, Kim JK, Choi JW, Choi BS, Pyun HW, Choi YJ, et al. Intracranial stenting of severe symptomatic intracranial stenosis: results of 100 consecutive patients. AJNR Am J Neuroradiol 2008:29:781-785

4. Kim KS, Hwang DH, Ko YH, Kang IW, Lee ES, Han YM, et al. Usefulness of stent implantation for treatment of intracranial atherosclerotic stenoses. Neurointervention 2012;7:27-33

5. Chang HW, Shin SH, Suh Sl, Jeong HW, Suh DC. Recommendations for carotid stenting in Korea. Neurointervention 2015;10:713

6. Connors JJ 3rd, Wojak JC, Hoppe BH. The technique of endovascular intracranial revascularization. Front Neuro/ 2014;5:246

7. Chaudhry NS, Orning JL, Shakur SF, Amin-Hanjani S, Aletich VA, Charbel FT, et al. Safety and efficacy of balloon angioplasty of the anterior cerebral artery for vasospasm treatment after subarachnoid hemorrhage. Interv Neuroradiol 2017;23:372-377

8. Bartolini B, Blanc R, Pistocchi S, Redjem H, Ciccio G, Piotin M. TransForm occlusion balloon catheter for the treatment of intracranial aneurysms, initial experience. Interv Neuroradiol 2015;21:155-160

9. Okamura A, Kuroki K, Shinagawa K, Yamada N. Simple aspiration with balloon catheter technique (simple ABC technique) against proximal internal carotid artery occlusion in cases of cardiogenic cerebral embolism. Interv Neuroradiol 2018;24:317321

10. Rigatelli G, Dell'Avvocata F, Giordan M, Cardaioli P. Air embolism caused by balloon rupture resolved by manual thrombectomy catheter aspiration. Cardiovasc Revasc Med 2011;12:129-130

11. Kahn JK, Hartzler GO. The spectrum of symptomatic coronary 
air embolism during balloon angioplasty: causes, consequenc-

es, and management. Am Heart J 1990;119:1374-1377

12. O'Neill L, Sowbhaga $V$, Owens P. Fracture, inflation and floatation embolisation of PTCA balloon. BMJ Case Rep 2015:2015:bcr2014205307

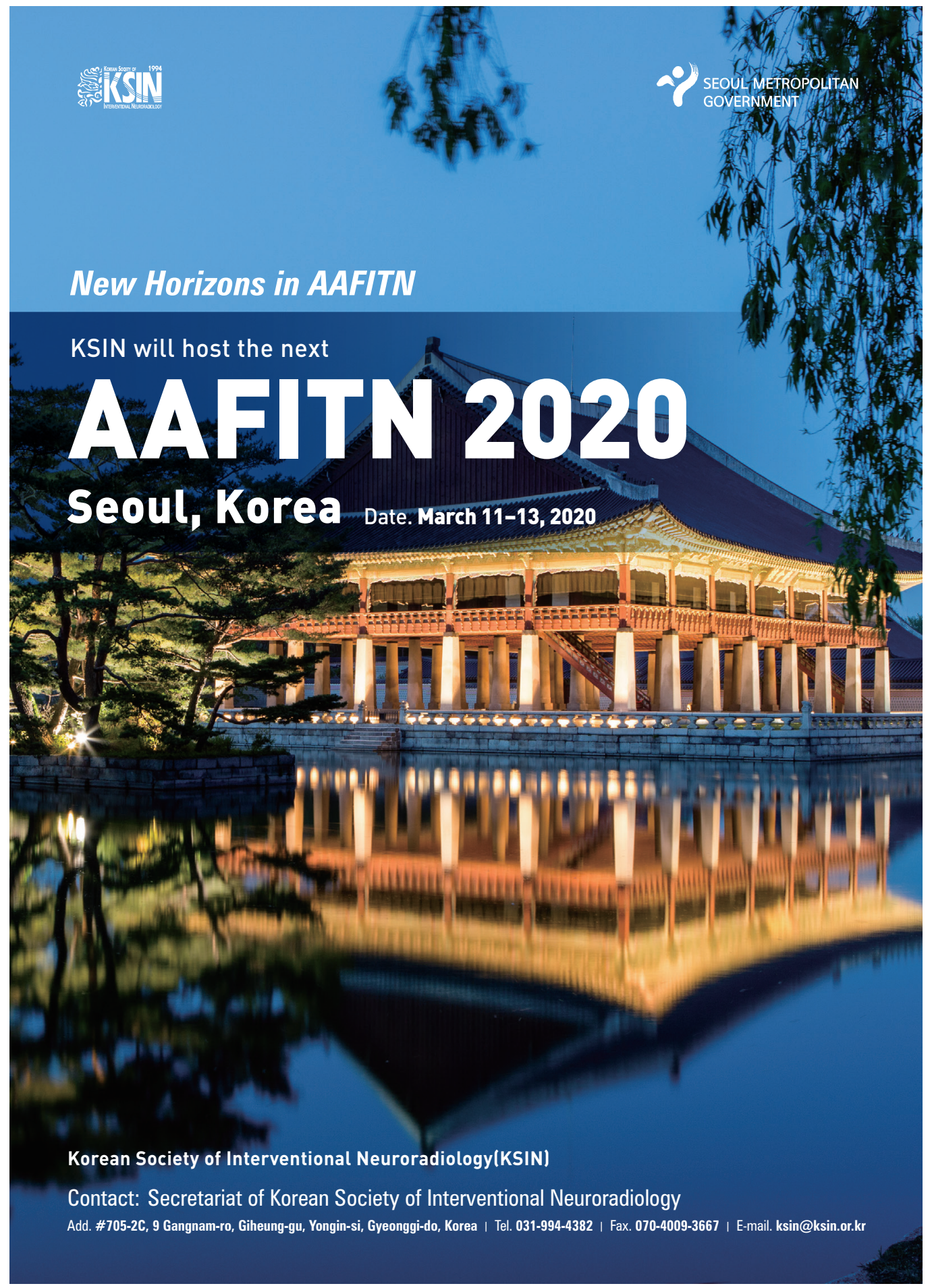

